\title{
Editorial: Smart Approaches to Predict Urban Flooding: Current Advances and Challenges
}

\author{
Mingfu Guan ${ }^{1 *}$, Qiuhua Liang ${ }^{2}$ and Jingming Hou ${ }^{3}$ \\ ${ }^{1}$ Department of Civil Engineering, University of Hong Kong, Pokfulam, Hong Kong, ${ }^{2}$ School of Architecture, Building and Civil \\ Engineering, Loughborough University, Loughborough, United Kingdom, ${ }^{3}$ State Key Laboratory of Eco-Hydraulics in \\ Northwest Arid Region of China, Xi'an University of Technology, Xi'an, China
}

Keywords: urban flooding, stormwater runoff, flood modeling, pollutant transport, data-driven

\section{Editorial on the Research Topic}

\section{Smart Approaches to Predict Urban Flooding : Current Advances and Challenges}

\section{OPEN ACCESS}

Edited and reviewed by:

Nick Van De Giesen,

Delft University of Technology,

Netherlands

*Correspondence:

Mingfu Guan

mfguan@hku.hk

Specialty section:

This article was submitted to

Hydrosphere,

a section of the journal

Frontiers in Earth Science

Received: 17 March 2021

Accepted: 22 March 2021

Published: 20 April 2021

Citation:

Guan M, Liang Q and Hou J (2021)

Editorial: Smart Approaches to Predict

Urban Flooding: Current Advances and Challenges.

Front. Earth Sci. 9:681751

doi: 10.3389/feart.2021.681751
Urban flooding induced by cloudburst has caused widespread disruption, damages, and environmental impact worldwide. In the context of climate change and rapid urbanization, it is expected that urban flooding will increase in both severity and frequency in the future (IPCC, 2013). In urban areas, concentration of populations, dense properties, key infrastructure systems, and businesses make flood impact be particularly severe, including both direct damage and indirect consequences such as loss of productivity and business opportunities. In addition, the potential risk to public health associated with exposure to contaminants due to urban flooding has also been increasingly recognized worldwide (Van der Vliet et al., 2014; Sales-Ortells and Medema, 2015). Urban flooding and their complex interaction with social and engineering systems impose great challenges on the conventional approaches both to short-term forecasting for emergency response and long-term planning for climate adaptation. There are clear technical challenges and knowledge gaps in understanding and predicting rainfall-induced urban flooding and the associated processes, e.g., pollutant transport.

This Research Topic compiles 11 contributions covering topics related to enhancing capability for urban flood modeling, the importance of data support in urban flood modeling, as well as the improved understanding of the fundamental urban runoff dynamics and associated processes. The papers report new approaches and demonstrate how urban flooding and associated runoff quality issues can be reasonably modeled and understood.

\section{ENHANCEMENT OF URBAN FLOOD MODELING}

Urban flood models solving the Shallow Water Equations (SWEs) have demonstrated their robustness in predicting detailed flood hydrodynamics in urban areas. Using a two-dimensional SWE model, Wang et al. simulates the inundation process due to dam-break in the downstream areas of Minzhi Reservoir in Shenzhen, China. Therein, urban structures are represented by using a refined grid with an unstructured mesh of triangular cells constrained by building walls. Currently, urban flood models are mostly two-dimensional, whereas $\mathrm{Yu}$ et al.develops a three-dimensional hydrodynamic model to look into the dam-break-induced flood dynamics and its interaction with buildings. The study exerts a simpler and more efficient algebraic Volume of Fluid method for free surface tracking. Alternatively, La Rocca et al. attempts the Discrete Boltzmann Equation (DBE) which 
consists of linear advection equations, to reproduce urban inundation processes. The study indicates that the DBE can be used to efficiently solve the SWEs for flood modeling and the resulting DBE model is validated against an idealized urban flood test case. Quantification of drainage capability in an urban flood model is crucial for accurate simulation of urban inundation, particularly at local scale. For this, Li et al. proposes an inletdrainage approach to consider the drainage effects by subtracting the mass of water into drainage systems in particular parts of the domain, e.g., the areas with gullies or drainage inlets, providing a simple way to simulate the coupled rainfall-runoff-drainageinundation processes.

Moreover, recent development has also been focused on the application of deep/machine learning approaches to support flood prediction. For example, Kabir et al. (2020) has recently developed a deep convolutional neural network (CNN) method for rapid prediction of flood inundation at a large scale. In this specific topic, Lin et al. also attempts to develop an Artificial neural network (ANN) for directly producing high-resolution inundation maps from multiple discharge inputs. Testing against historic flood events, it is shown that the ANN model is capable of predicting the maximum inundation extents reasonably well. The prediction quality may be further improved by introducing clustering for preprocessing discharge curves before model training.

\section{DATA AND URBAN FLOOD MODELING}

Data is crucial for urban flood prediction in real-world applications, but data to support high-resolution simulations is still largely scarce for urban areas. Despite the high recurrence frequency of urban floods, field observations during urban flooding are rarely available for model calibration and validation. Petersson et al. integrates data acquisition with survey design and quality assurance based on community mapping into flood model development and prediction. The study indicates that citizen science data from community mapping is affordable, comprehensible, quality assured and open source, making it applicable to support flood prediction in resourcestrained contexts. Moreover, to evaluate the influence of data precision and generalization on urban flood modeling in realworld events, $\mathrm{Xu}$ et al. also applies a combined modeling approach to an urban area in Beijing through multi-mode surface data generalization and detailed urban flood modeling with pipe networks. When high-quality monitored data is lacking, modeling may provide valuable support for design flood estimation in urban environments. To verify this, Ball et al. presents an analysis of continuous and event-based modeling undertaken for design flood estimation in an urban catchment located in Sydney, Australia. It is shown that frequency analysis of the predicted flows from the continuous modeling resembles the frequency analysis of the recorded data more closely.

\section{RUNOFF QUALITY ASSOCIATED WITH URBAN FLOODING}

Urbanization generally creates significant changes to land surface, and anthropogenic activities and may cause remarkable changes in urban stormwater quality and quantity (Guan et al., 2015a). Stormwater runoff pollution commonly occurs before or after an urban flood event, and it is considered as the primary form of pollutant transport in urban environments. For example, Pan et al. analyses the migration characteristics of stormwater runoff pollutants based on field data in five different underlying surfaces of Guangzhou. It is verified that stormwater runoff causes urban non-point source pollution that increasingly introduces contaminants to urban water bodies and impedes sustainable development. On the stormwater quality issue, Zhang et al. proposes a $2 \mathrm{D}$ coupled model of flow and pollutant transport to reproduce the urban stormwater dynamics and associated pollutant transport process. It is shown that buildings may slow down pollutant transport, especially when the buildings are staggered.

Blue-green infrastructure (BGI) or sponge city has become increasingly considered as an effective option for managing urban flooding and runoff quality in urbanized landscapes (Guan et al., 2015b; Golden and Hoghooghi, 2018; Ahilan et al., 2019). In order to verify the effects of sponge city measures on soil moisture and water quality, Jia et al. conducts comprehensive analysis on land use change processes, the temporal and spatial soil water content change, as well as water quality change with different measures during a rainfall event in Guyang, China. It is found that the development of sponge city could improve urban ecological environment and hydrological conditions in the Loess Plateau and increase potential utilization of urban rainwater resources.

\section{AUTHOR CONTRIBUTIONS}

MG wrote the draft of the manuscript. QL and JH edited and commented on the draft. All authors approved the manuscript for publication.

\section{FUNDING}

This work was funded by the Early Career Scheme Grant from Hong Kong Research Grant Council (No. 27202419).

\section{ACKNOWLEDGMENTS}

We thank all the reviewers for reviewing the papers in the Research Topic. 


\section{REFERENCES}

Ahilan, S., Guan, M., Wright, N., Sleigh, A., Allen, D., Arthur, S., et al. (2019). Modelling the long-term suspended sedimentological effects on stormwater pond performance in an urban catchment. J. Hydrol. 571, 805-818. doi: $10.1016 /$ j.jhydrol.2019.02.002

Golden, H. E., and Hoghooghi, N. (2018). Green infrastructure and its catchmentscale effects: an emerging science. Wiley Interdisc. Rev. Water 5:e1254. doi: $10.1002 /$ wat 2.1254

Guan, M., Sillanpää, N., and Koivusalo, H. (2015a). Modelling and assessment of hydrological changes in a developing urban catchment. Hydrol. Process. 29, 2880-2894. doi: 10.1002/hyp.10410

Guan, M., Sillanpää, N., and Koivusalo, H. (2015b). Assessment of LID practices for restoring pre-development runoff regime in an urbanized catchment in southern Finland. Water Sci. Technol. 71, 1485-1491. doi: 10.2166/wst.2015.129 IPCC (2013) Climate Change 2013: Synthesis Report. Valencia.

Kabir, S., Patidar, S., Xia, X., Liang, Q., Neal, J., and Pender, G. (2020). A deep convolutional neural network model for rapid prediction of fluvial flood inundation. J. Hydrol. 590:125481. doi: 10.1016/j.jhydrol.2020.125481
Sales-Ortells, H., and Medema, G. (2015). Microbial health risks associated with exposure to stormwater in a water plaza. Water Res. 74, 34-46. doi: 10.1016/j.watres.2015.01.044

Van der Vliet, J. C., Van Knapen, F., and de Roda Husman, A. M. (2014). Quantitative assessment of infection risk from exposure to waterborne pathogens in urban floodwater. Water Res. 48, 90-99. doi: 10.1016/j.watres.2013.0 9.022

Conflict of Interest: The authors declare that the research was conducted in the absence of any commercial or financial relationships that could be construed as a potential conflict of interest.

Copyright $\odot 2021$ Guan, Liang and Hou. This is an open-access article distributed under the terms of the Creative Commons Attribution License (CC BY). The use, distribution or reproduction in other forums is permitted, provided the original author(s) and the copyright owner(s) are credited and that the original publication in this journal is cited, in accordance with accepted academic practice. No use, distribution or reproduction is permitted which does not comply with these terms. 